02

\title{
Электронная структура полианилина, модифицированного солями меди и циркония
}

\author{
() В.А. Шматко ${ }^{1}$, Т.Н. Мясоедова ${ }^{2}$, Г.Э. Яловега ${ }^{1}$ \\ ${ }^{1}$ Южный федеральный университет, \\ 344090 Ростов-на-Дону, Россия \\ ${ }^{2}$ Институт нанотехнологий, электроники и приборостроения ЮФУ, \\ 347928 Таганрог, Россия \\ e-mail: shmatko86@mail.ru
}

Поступила в редакцию 03.12.2019 г.

В окончательной редакции 31.01.2020 г.

Принята к публикации 05.02.2020 г.

Спектроскопически исследованы особенности электронной структуры и химических связей композитов ПАНИ-Me $(\mathrm{Me}-\mathrm{Cu}, \mathrm{Zr})$. Для исследований использовались рентгеновская спектроскопия поглощения, рентгеновская фотоэлектронная спектроскопия, ИК спектроскопия. Установлено, что вне зависимости от типа используемой модифицирующей добавки полианилин в композитах находится в частично окисленной форме, однако в ПАНИ- $\mathrm{Zr}$ более окислен, чем в ПАНИ-Cu. Определены химические состояния азота в композитах, наблюдается различное соотношение нейтральных и заряженных азотогрупп.

Ключевые слова: полианилин, композиты на основе полианилина, XANES, XPS.

DOI: $10.21883 /$ OS.2020.05.49319.328-19

\section{Введение}

Проводящие полимеры и композиты на их основе, обладающие химической стабильностью, перспективны для применения в органической электронике, при создании суперконденсаторов, топливных элементов, сенсоров, биосенсоров и др. [1-4]. Типичными представителями этого класса полимеров являются полипиррол, полианилин (ПАНИ, РАNI), политиофен, полипарафенилен и некоторые их производные. Несмотря на то, что полианилин был получен давно и достаточно хорошо изучен, в настоящее время продолжается активный поиск новых путей его синтеза и создания композитов на его основе с целью получения материалов с улучшенными характеристиками [5]. Полимерная цепь полианилина представляет собой повторяющиеся звенья, включающие чередующиеся бензоидные (восстановленные) и хиноидные (окисленные) фрагменты. В зависимости от содержания и соотношения этих фрагментов говорят о различных формах и степени окисления полианилина. Так, полимерная цепь, состоящая только из бензоидных фрагментов, соответствует полностью восстановленной форме полианилина (лейкоэмералдин), полностью окисленный полианилин (пернигранилин) состоит только из хиноидных фрагментов. Особый интерес представляет полуокисленный полианилин, состоящий из чередующихся бензоидных и хиноидных фрагментов с соотношением 1:1 [6] . Свойства полианилина, в частности электрические, определяются его формой, степенью окисления и протонирования, микроструктурой. Так как формирование физико-химических свойств полианилина происходит в процессе синтеза, то на свойства полимера первостепенное воздействие оказывают параметры и методы синтеза. Так, для изменения электрофизических и физико-химических свойств, увеличения термической стабильности, ПАНИ допируют протонными кислотами или создают композитные материалы на основе полианилина и неорганических материалов, таких как соли металлов [7,8]. Получение композитов на основе полианилина с различными свойствами достигается путем варьирования модифицирующих добавок и температур синтеза. Для модифицирования полианилина широко используются соединения меди и циркония. Использование фосфата циркония при химической полимеризации анилина позволило авторам работы [7] получить композит PANI-ZrP с содержанием проводящей формы полианилина. Модифицирование полианилина наночастицами оксида циркония $\mathrm{ZrO}_{2}$ позволяет увеличить термостабильность и получить композит с хорошей проводимостью [9]. Химическая полимеризация анилина с добавлением сульфата меди приводит к ухудшению термостабильности, а проводимость материала зависит от концентрации $\mathrm{CuSO}_{4} \cdot 5 \mathrm{H}_{2} \mathrm{O}$ [10]. Модифицирование полианилина хлоридом меди $\mathrm{CuCl}_{2}$ методом обратной эмульсионной полимеризации приводит к уменьшению проводимости материала и термостабильности, однако композиты растворимы в обычных органических растворителях [11]. С другой стороны, легирование полианилина хлоридом меди $\mathrm{CuCl}_{2}$ при химической полимеризации позволяет повысить термостабильность и проводимость полианилина [12].

Разработка методов синтеза композитов с заданными свойствами неразрывно связана с исследованиями особенностей влияния параметров синтеза на элек- 
тронную структуру и микроструктуру получаемых материалов. Для исследования электронной структуры, химических связей, определения формы полианилина чрезвычайно информативными являются спектроскопические методы исследования [7,8,13]. Ранее в работах [14-16] мы исследовали композиты на основе полианилина и хлоридов металлов спектроскопическими методами.

В настоящей работе представлены результаты исследования особенностей электронной структуры, химических связей и морфологии композитов на основе полианилина, термостатированных при температуpe $\left(90^{\circ} \mathrm{C}\right)$, в зависимости от типа модифицирующей добавки $\left(\mathrm{CuCl}_{2} \cdot 2 \mathrm{H}_{2} \mathrm{O}\right.$ и $\left.\mathrm{ZrOCl}_{2} \cdot 8 \mathrm{H}_{2} \mathrm{O}\right)$ методами рентгеновской фотоэлектронной спектроскопии, рентгеновской спектроскопии поглощения, ИК спектроскопии и сканирующей электронной микроскопии.

\section{Получение образцов и техника эксперимента}

Композиты ПАНИ-Ме (Me - $\mathrm{Cu}, \mathrm{Zr})$ получены методом химического окисления анилина без добавления какой-либо кислоты. Для получения образцов персульфат калия растворяли в дистиллированной воде, в раствор при постоянном помешивании добавляли анилин. На стадии полимеризации анилина вносили неорганические компоненты - водные растворы дигидрата хлорида меди $\mathrm{CuCl}_{2} \cdot 2 \mathrm{H}_{2} \mathrm{O}$ (образец ПАНИ- $\mathrm{Cu}$ ) или оксихлорида циркония $\mathrm{ZrOCl}_{2} \cdot 8 \mathrm{H}_{2} \mathrm{O}$ (образец ПАНИ- $\mathrm{Zr}$ ) с концентрацией $0.5 \mathrm{~mol} / 1$. Далее образцы термостатировали в течение $4 \mathrm{~h}$ при температуре $90^{\circ} \mathrm{C}$. Соотношение компонент подбиралось таким образом, чтобы не препятствовать процессу полимеризации анилина, что позволило совместить процессы полимеризации и модифицирования.

Микроскопические исследования проводились на микроскопе ZESS LEO 1560 в режиме регистрации вторичных электронов при ускоряющем напряжении $5 \mathrm{kV}$.

Спектры рентгеновского поглощения NEXAFS (near edge X-ray absorption fine structure) К-краев азота в композитах ПАНИ-Ме получены в режиме регистрации выхода оже-электронов при падении пучка излучения относительно поверхности образца $60^{\circ}$ на станции „Materials science“ синхротронного центра Elettra (Триест, Италия). Давление остаточных газов в измерительной камере составляло $1.7 \cdot 10^{-9}$ mbar. Рентгеновские спектры поглощения XANES (X-ray absorption near edge structure) К-краев металлов были измерены на станции „Структурное материаловедение“ Курчатовского источника синхротронного излучения (Москва, Россия). Регистрация рентгеновских спектров поглощения проводилась при комнатной температуре в режиме пропускания.

Рентгеновские фотоэлектронные спектры (XPS, X-ray photoelectron spectroscopy) N $1 s$ также были получены

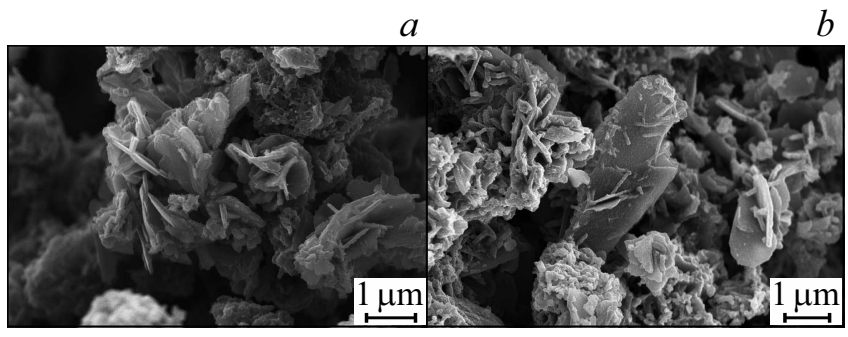

Рис. 1. Микрофотографии ПАНИ-Сu (a), ПАНИ-Zr $(b)$.

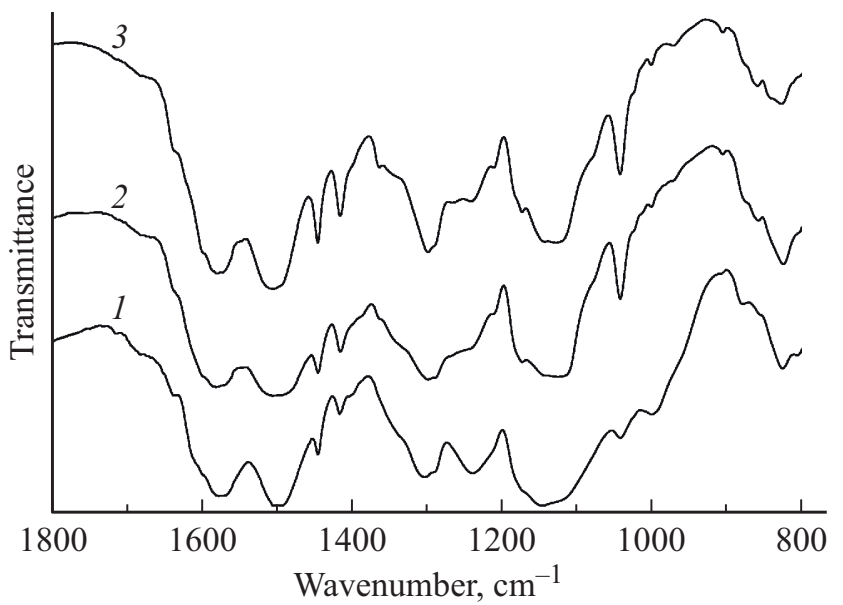

Рис. 2. Инфракрасные спектры композитов ПАНИ-Zr (1), ПАНИ-Сu (2) в сопоставлении со спектром ПАНИ (3).

на станции „Materials science“ синхротронного центра Elettra (Триест, Италия) при энергии падающего излучения $630 \mathrm{eV}$.

Измерения ИК спектров проводились на ИК фурьеспектрометре ФМС 12-01. Измеряемые порошки были спрессованы в таблетки с добавлением $\mathrm{KBr}$ в соотношении $1: 200$.

\section{Результаты и обсуждения}

Композиты ПАНИ-Ме представляют собой смесь агломератов палочкообразных и пластинчатых микроструктур, где пластинчатые структуры - это металлсодержащая компонента, а палочкообразные - полианилин (рис. 1). Однако следует заметить, что в ПАНИ-Zr образуются смешанные агломераты из палочкообразных и пластинчатых микроструктур, в то время как в ПАНИ- $\mathrm{Cu}$ преимущественно образуются отдельные цветочнообразные агломераты, состоящие только из пластинчатых микроструктур металлсодержащей компоненты, которые распределены среди агломератов палочкообразных структур ПАНИ [14].

Инфракрасная спектроскопия была использована для исследования особенностей химических связей в композитах. Каждая из форм полианилина имеет свои характерные особенности в ИК спектрах. На рис. 2 
представлены ИК спектры пропускания композитов ПАНИ-Cu, ПАНИ-Zr и чистого ПАНИ. Видно, что спектры ПАНИ и ПАНИ-Сu обладают практически одинаковым набором полос поглощения. Спектр образца ПАНИ-Zr отличается от этих спектров в области волновых чисел менее $1300 \mathrm{~cm}^{-1}$. Во всех спектрах присутствуют основные полосы при 1580 и $1504 \mathrm{~cm}^{-1}$, которые соответствуют колебаниям хиноидного $(\mathrm{N}=\mathrm{Q}=\mathrm{N})$ и бензольного $(\mathrm{N}-\mathrm{B}-\mathrm{N})$ колец соответственно [17]. Интенсивности ИК полос, характерных для колебаний хиноидных и бензоидных звеньев, позволяют оценить их соотношение в слое полимера [18], а также степень окисления полимера. Для всех представленных спектров интенсивность бензольной компоненты немного меньше, чем у хиноидной компоненты. Наличие обеих полос указывает на частично окисленное состояние полианилина во всех образцах. Анализ соотношения интенсивностей показал, что степень окисления полианилина в ПАНИ $-\mathrm{Zr}$ больше, чем в ПАНИ $-\mathrm{Cu}$, и близка к 0.5. Это соответствует полианилину в эмералдиновой форме. Полоса при $1299 \mathrm{~cm}^{-1}$ относится к колебаниям связи $\mathrm{C}-\mathrm{N}$. Для образца ПАНИ $-\mathrm{Zr}$ эта полоса сдвигается на $7 \mathrm{~cm}^{-1}$ в сторону больших значений волновых чисел. Полоса поглощения около $1240 \mathrm{~cm}^{-1}$ связана с колебаниями связи $\mathrm{C}-\mathrm{N}^{+}$[17]. Полоса поглощения при $1128 \mathrm{~cm}^{-1}$ в спектре ПАНИ, по-видимому, связана с колебаниями фрагмента $\mathrm{B}-\mathrm{NH}^{+}-\mathrm{Q}[19]$. При переходе к композитам происходит сдвиг полосы в сторону меньших значений волнового числа для ПАНИ-Сu и в сторону больших значений волнового числа для ПАНИ-Zr. Полоса поглощения при $830 \mathrm{~cm}^{-1}$ соответствует колебаниям связи $\mathrm{C}-\mathrm{H}$. Приведенные спектральные данные указывают на то, что полимеризация анилина в присутствии $\mathrm{CuCl}_{2} \cdot 2 \mathrm{H}_{2} \mathrm{O}$ или $\mathrm{ZrOCl}_{2} \cdot 8 \mathrm{H}_{2} \mathrm{O}$ с дальнейшим термостатированием при $90^{\circ} \mathrm{C}$ приводит к образованию частично окисленной формы полианилина в композитах ПАНИ-Сu и ПАНИ-Zr. Причем степень окисления полианилина в ПАНИ $-\mathrm{Zr}$ больше, чем в ПАНИ-Cu. Сдвиг полос поглощения, соответствующих азотным связям, свидетельствует о взаимодействии катионов металлов с атомами азота полимерной цепи [20,21].

Электронная структура азота, его химическое состояние и химические связи в полианилине и композитах на его основе оказывают определяющее влияние на свойства материалов. Отличными комплементарными методами исследования различных состояний окисления атомов азота в цепи полианилина являются методы рентгеновской спектроскопии поглощения и рентгеновской фотоэлектронной спектроскопии $[7,13,22]$.

На рис. 3 приведены спектры NEXAFS К-края азота в ПАНИ-Cu, ПАНИ-Zr. Тонкая структура спектров формируется в результате разрешенных электронных переходов с уровня $1 s$ в зону свободных состояний $\sigma^{*}$ и $\pi^{*}$. Как видно из рисунка, спектры совпадают в области широкого максимума при энергии $\sim 408 \mathrm{eV}$, который

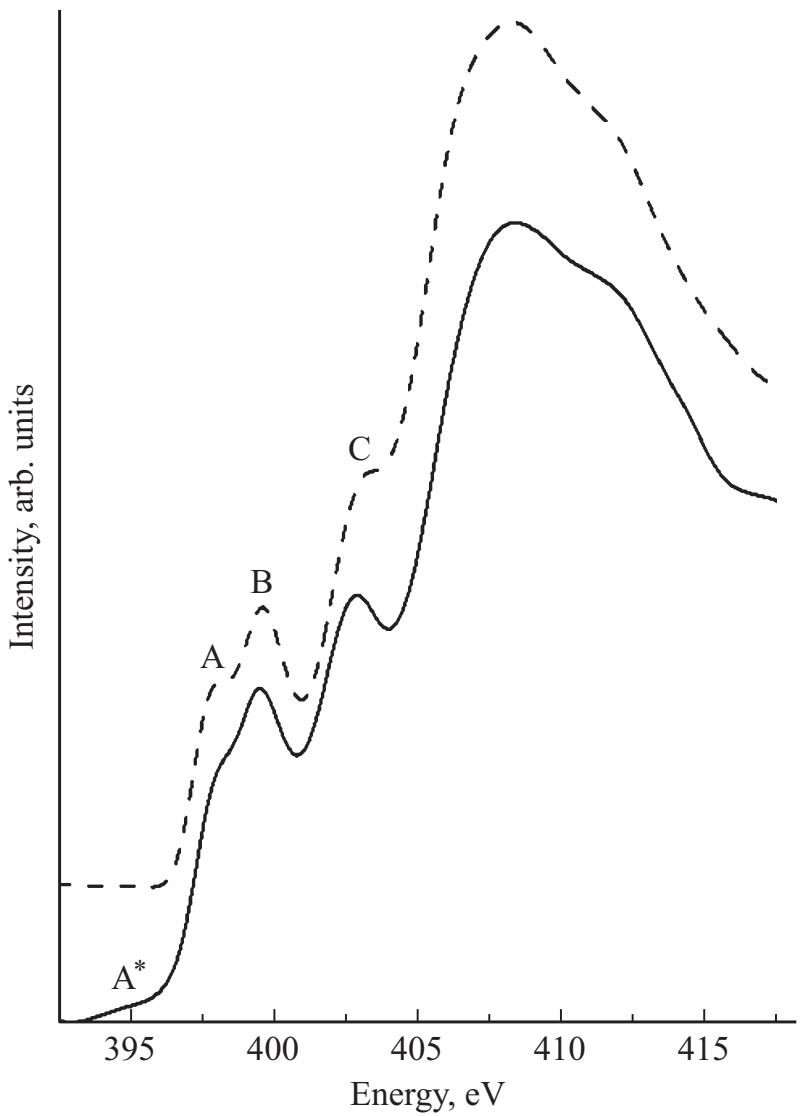

Рис. 3. Спектры NEXAFS K-края азота в ПАНИ-Cu (сплошная линия) и ПАНИ-Zr (штриховая линия).

связан с делокализованными электронными состояниями $\sigma^{*}$ [23] (электронные переходы $\mathrm{N} 1 s \rightarrow \sigma^{*}$ ), тогда как в области состояний $\pi^{*}$ (электронные переходы $\mathrm{N} 1 s \rightarrow \pi^{*}$ ) в спектрах наблюдаются различия.

В низкоэнергетической области спектров наблюдается формирование трех спектральных особенностей (пики А, В, С), которые относятся к иминным и аминным группам. Наличие спектральных особенностей, относящихся как к иминным, так и аминным группам, подтверждает частично окисленное состояние полианилина в составе композита вне зависимости от модифицирующей добавки. Однако необходимо отметить, что для образца ПАНИ-Сu особенность С сдвигается в низкоэнергетическую область. Кроме того, наблюдается уменьшение интенсивности пика А с одновременным ростом интенсивности пика $\mathrm{C}$ в спектре ПАНИ-Cu и обратная ситуация для образца ПАНИ-Zr. Перераспределение интенсивности спектральных особенностей в спектрах ПАНИ $-\mathrm{Cu}$ и ПАНИ $-\mathrm{Zr}$, относящихся к различным азотогруппам, говорит о различном соотношении этих групп в образцах. Кроме того, в отличие от спектра ПАНИ-Zr в спектре ПАНИ-Сu присутствует предпик $\mathrm{A}^{*}$. Он, вероятно, обусловлен формированием дополнительных состояний у дна зоны проводимости. 


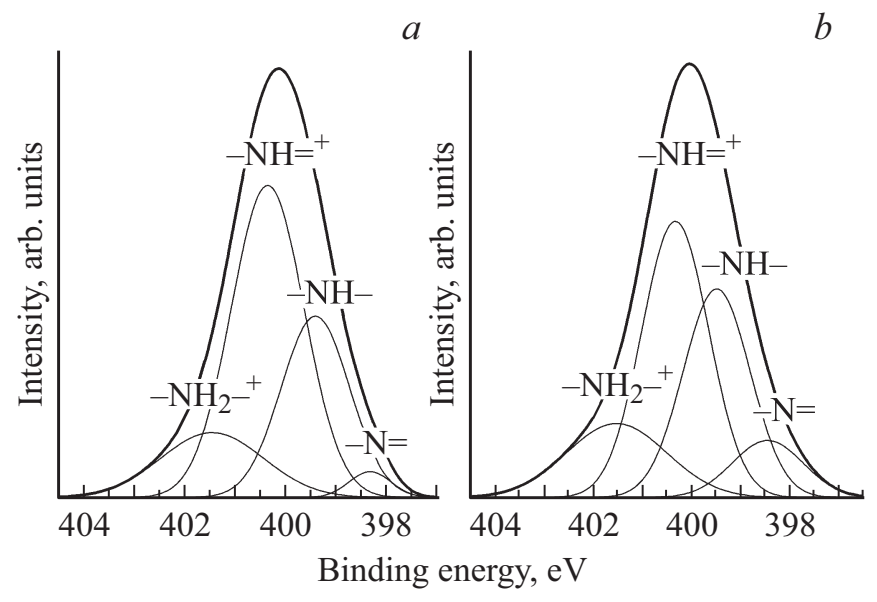

Рис. 4. Спектры XPS $\mathrm{N} 1 s$ композитов ПАНИ- $\mathrm{Cu}$ (a), ПАНИ-Zr $(b)$.

Рентгеновские фотоэлектронные спектры линии N1s ПАНИ-Cu, ПАНИ-Zr представлены на рис. 4. Линия $\mathrm{N} 1 s$ имеет максимум на энергии связи около $400 \mathrm{eV}$. Разложение XPS выполнено с помощью гауссовых кривых и алгоритма Левенбурга-Марквардта с использованием программы Fityk [24]. Анализ XPS позволил распознать наличие различных азотогрупп в составе композитов и определить их вклад. В спектрах линии $\mathrm{N} 1 s$ обоих композитов присутствуют четыре компоненты, связаные с нейтральными и положительно заряженными иминными и аминными группами $[13,23,25]$. Иминный азот проявляется в спектрах в виде слабоинтенсивной компоненты в низкоэнергетической области спектров N $1 s(398.4 \mathrm{eV})$. Компонента, соответствующая азоту в аминной группе $(399.4 \mathrm{eV})$, более интенсивная и вносит весомый вклад в результирующий спектр обоих образцов. Компоненты при высоких энергиях связаны с $=\mathrm{NH}^{+}-$и $-\mathrm{NH}_{2}^{+}$группами. Как можно видеть, в целом характер соотношения интенсивностей компонент сохраняется между образцами. Однако для спектра ПАНИ-Zr наблюдается рост вклада азота в нейтральных азотогруппах. Кроме того, соотношение вкладов нейтральных и протонированных азотогрупп говорит о частично окисленном состоянии полианилина в обоих композитах, причем степень окисления зависит от типа модифицирующей добавки и полианилин в ПАНИ- $\mathrm{Zr}$ более окислен, чем в ПАНИ- $\mathrm{Cu}$.

Степень окисления металлов в композитах была исследована на основе анализа спектров рентгеновского поглощения XANES K-края меди и циркония. На рис. 5, $a$ представлены спектры поглощения композита ПАНИ-Сu и стандартных соединений меди $\left(\mathrm{CuCl}_{2} \cdot 2 \mathrm{H}_{2} \mathrm{O}, \mathrm{CuO}, \mathrm{Cu}_{2} \mathrm{O}\right)$. Как можно видеть, спектр композита не совпадает ни с одним из спектров стандартов, что говорит об отличиях локальной структуры меди в ПАНИ-Сu и дигидрохлориде меди, оксидах $\mathrm{CuO}, \mathrm{Cu}_{2} \mathrm{O}$. Форма спектра ПАНИ-Cu, энергетическое положение края поглощения $(8984.5 \mathrm{eV})$, которое определялось по первому максимуму производной, и „белой линии“ $(8997.3 \mathrm{eV})$, наличие предкраевых особенностей (пик А и плечо В) говорят о том, что ионы меди в ПАНИ-Сu находятся в окисленной форме $2^{+}$. Интенсивность и положение пиков А и В в спектрах меди являются индикатором количества и расположения лигандов атомов меди. Плечо В со стороны низких энергий главного максимума поглощения связано с переносом заряда лиганд-металл и указывает на наличие атомов в аксиальных позициях и 6-кратную координацию иона меди [26], что также подтверждается слабоинтенсивным пиком А. Отличия спектра композита от спектров стандартов связаны с тем, что в композите присутствуют ионы меди с различной локальной структурой. Мы предполагаем, что ионы меди внутри пластинчатой медьсодержащей микроструктуры имеют то же локальное окружение, что и в $\mathrm{CuCl}_{2} \cdot 2 \mathrm{H}_{2} \mathrm{O}$, в то время как локальное окружение ионов меди на поверхности этой микроструктуры отличается из-за соседствующих микроструктур полианилина. В этом случае в ближайшее окружение меди могут входить атомы азота полианилина [27].

На рис. 5, $b$ сопоставлены экспериментальные спектры XANES для ПАНИ-Zr и $\mathrm{ZrO}_{2}, \mathrm{ZrOCl}_{2} \cdot 8 \mathrm{H}_{2} \mathrm{O}$. Спектр композита по положениям „белой линии“ и края поглощения согласуется со спектром $\mathrm{ZrOCl}_{2} \cdot 8 \mathrm{H}_{2} \mathrm{O}$, что говорит об окисленной форме циркония $4^{+}[15,28]$. Однако изменение локальной структуры циркония при формировании композита приводит к отличиям спектров композита и оксихлорида циркония. Вероятно, изменения в локальной структуре ионов циркония также связаны с влиянием соседствующих полимерных цепей. Смещение плеча $\mathrm{B}$ и пика $\mathrm{C}$ в область высоких энергий указывает на уменьшение межатомных расстояний цир-
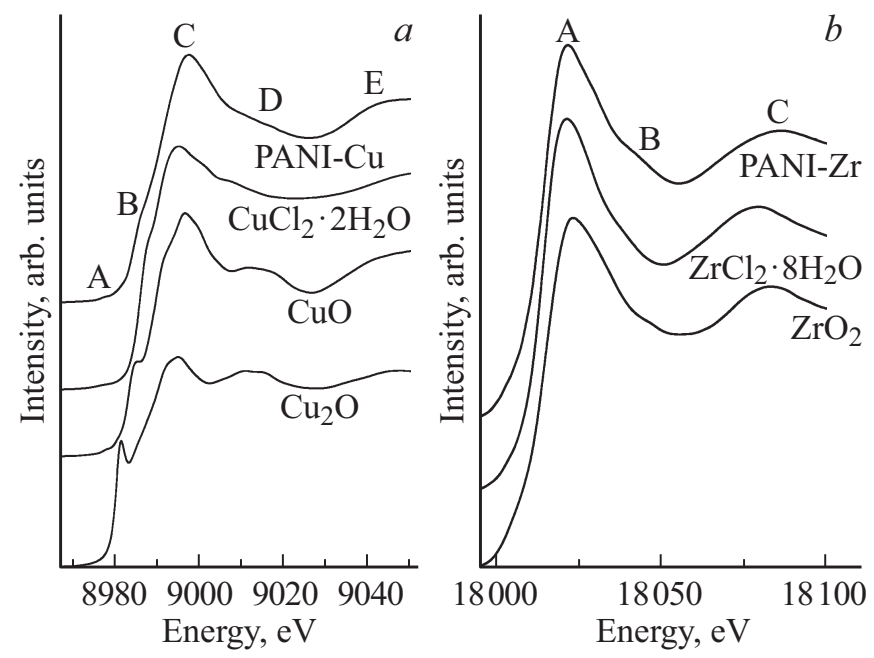

Рис. 5. Спектры XANES Cu K-края в ПАНИ- $\mathrm{Cu}$ в сопоставлении со спектрами стандартных соединений $\mathrm{CuCl}_{2} \cdot 2 \mathrm{H}_{2} \mathrm{O}, \mathrm{CuO}$ и $\mathrm{Cu}_{2} \mathrm{O}(a)$ и спектры $\mathrm{Zr}$ К-края в ПАНИ- $\mathrm{Zr}$ в сопоставлении c $\mathrm{ZrO}_{2}, \mathrm{ZrOCl}_{2} \cdot 8 \mathrm{H}_{2} \mathrm{O}(b)$. 
кония и ближайших соседей в сравнении с расстояниями $\mathrm{Zr}-\mathrm{O}$ в $\mathrm{ZrOCl}_{2} \cdot 8 \mathrm{H}_{2} \mathrm{O}$.

\section{Заключение}

Методами рентгеновской спектроскопии поглощения, рентгеновской фотоэлектронной спектроскопии, ИК спектроскопии исследованы особенности электронной структуры композитных материалов на основе полианилина в зависимости от модифицирующей добавки. Установлено, что бескислотный способ полимеризации анилина с использованием в качестве модифицирующей добавки $\mathrm{CuCl}_{2} \cdot \mathrm{H}_{2} \mathrm{O}$ и $\mathrm{ZrOCl}_{2} \cdot 8 \mathrm{H}_{2} \mathrm{O}$ при температуре термостатирования $90{ }^{\circ} \mathrm{C}$ позволяет получать композиты различной морфологии с содержанием частично окисленной формы полианилина. Степень окисления полианилина зависит от типа модифицирующей добавки и в ПАНИ-Zr выше, чем в ПАНИ-Cu. Степень окисления металлов не изменяется при формировании композитов, в ПАНИ-Сu входят двухвалентные ионы меди, а в ПАНИ-Zr - четырехвалентные ионы циркония. Исследования химических связей и электронной структуры показали, что для образца, полученного с добавлением оксихлорида циркония, характерно меньшее содержание протонированных азотогрупп, чем для образца, полученного с добавлением гидрохлорида меди.

\section{Благодарности}

Авторы выражают благодарность синхротронному центру Elettra (станция Material Science) и сотрудникам станции „Структурное материаловедение“ НИЦ „Курчатовский институт“, а также М.М. Бржезинской за проведение СЭМ-измерений.

\section{Финансирование работы}

Работа выполнена при финансовой поддержке гранта Президента МК-4933.2018.2 и частично в рамках Внутреннего гранта Южного федерального университета (ВнГр-07/2017-30).

\section{Конфликт интересов}

Авторы декларируют отсутствие явных и потенциальных конфликтов интересов, связанных с публикацией настоящей статьи.

\section{Список литературы}

[1] Pandey K., Yadav P., Mukhopadhyay I. // Phys. Chem. Chem. Phys. 2015. V. 17. P. 878. doi 10.1039/C4CP04321A

[2] Shah A.A., Yasmeen N., Rahman G., Mehmood M., Bilal S. // Electrochim. Acta. 2016. V. 188. P. 367. doi 10.1016/j.electacta.2015.11.140
[3] Lai J., Yi Y., Zhu P., Shen J., Wu K., Zhang L., Liu J. // J. Electroanal. Chem. 2016. V. 782. P. 138. doi 10.1016/j.jelechem.2016.10.033

[4] Suhail M.H., Ramadan A.A., Aziz S.B., Abdullah O.G. // J. Sci. Adv. Mater. Devices. 2017. V. 2. N 3. P. 301. doi 10.1016/j.jsamd.2017.07.003

[5] Wang D., Yang L., Liu H., Cao D. // J. Catal. 2019. V. 375. P. 249. doi 10.1016/j.jcat.2019.06.008

[6] do Nascimento G.M., Constantino V.R.L., Temperini M.L.A. // J. Phys. Chem. B. 2004. V. 108. P. 5564. doi 10.1021/jp037262i

[7] Izumi C.M.S., Constantino V.R.L., Temperini M.L.A. // J. Nanosci. Nanotechnol. 2008. V. 8. N 4. P. 1782. doi 10.1166/jnn.2008.014

[8] Izumi C.M.S., Constantino V.R.L., Ferreira A.M.C., Temperini M.L.A. // Synth. Met. 2006. V. 156. N 9-10. P. 654. doi 10.1016/j.synthmet.2005.12.023

[9] Huang H., Guo Z., Zhu W., Li F. // Adv. Mater. Res. 2011. V. 221. P. 302. doi 10.4028/www.scientific.net/AMR.221.302

[10] Upadhyaya M., Ahmed N., Deka R., Kakati D.K. // Iran Polym. J. 2012. V. 21. N 9. P. 601. doi 10.1007/s13726-0120064-8

[11] Ullah R., Bilal S., Ali K., Shah A.-ul-H.A. // Synth. Met. 2014. V. 198. P. 113. doi 10.1016/j.synthmet.2014.09.024

[12] Gupta K., Chakraborty G., Ghatak S., Jana P.C., Meika A.K. // J. Appl. Polym. Sci. 2010. V. 115. N 5 P. 2911. doi 10.1002/app.31380

[13] Hennig C., Hallmeier K.H., Szargan R. // Synth. Met. 1998. V. 92. N 2. P. 161 doi 10.1016/S0379-6779(98)80106-9

[14] Шматко В.А., Мясоедова Т.Н., Тригуб А.Л., Яловега Г.Э. // Поверхность. Рентгеновские, синхротронные и нейтронные исследования. 2020. № 5. С. 1. doi $10.31857 / \mathrm{S} 1028096020050179$

[15] Шматко В.А., Мясоедова Т.Н., Михайлова Т.А., Яловега Г.Э. // Конденсированные среды и межфазные границы. 2019. T. 21. № 4. C. 569. doi $10.17308 / \mathrm{kcmf} .2019 .21 / 2367$

[16] Шматко В.А., Мясоедова Т.Н., Моисеева Т.А., Чечеватов А.И., Яловега Г.Э. // Инженерный вестник Дона. 2018. № 4. ivdon.ru/ru/magazine/archive/n4y2018/5478

[17] Baibarac M., Baltog I., Lefrant S., Mevellec J.Y., Chauvet O. // Chem. Mater. 2003. V. 15. N 21. P. 4149. doi $10.1021 / \mathrm{cm} 021287 \mathrm{x}$

[18] Butoi B., Groza A., Dinca P., Balan A., Barna V. // Polymers. 2017. V. 9. N 12. P. 732. doi 10.3390/polym9120732

[19] Okotrub A.V., Asanov I.P., Galkin P.S., Bulusheva L.G., Chehova G.N., Kurenja A.G., Shubin Ju.V. // Polym. Sci. Ser. B. 2010. V. 52. N 1-2. P. 101. doi 10.1134/S1560090410010161

[20] Ivanova N.M., Soboleva E.A., Visurkhanova Y.A., Kirilyus I.V. // Russ. J. Electrochem. 2015. V. 51. P. 166. doi 10.1134/S1023193515020056

[21] Wang S., Tan Z., Li Y., Suna L., Zhang T. // Thermochim. Acta. 2006. V. 441. P. 191. doi 10.1016/j.tca.2005.05.020

[22] Bulusheva L.G., Fedorovskaya E.O., Okotrub A.V., Maximovskiy E.A., Vyalikh D.V., Chen X., Song H. // Phys. St. Sol. B. 2011. V. 248. N 11. P. 2484. doi 10.1002/pssb.201100108

[23] Ullah R., Bowmaker G.A., Laslau C., Waterhouse G.I.N., Zujovic Z.D., Ali K., Shah A.-U.-H.A., Travas-Sejdic J. // Synth. Met. 2014. V. 198. P. 203. doi 10.1016/j.synthmet.2014.10.005

[24] Wojdyr M. // J. Appl. Cryst. 2010. V. 43. P. 1126. doi $10.1107 / \mathrm{S} 0021889810030499$ 
[25] Mi H., Li F., He C., Chai X., Zhang Q., Li C., Li Y., Liu J. // Electrochim. Acta. 2016. V. 190. P. 1032. doi 10.1016/j.electacta.2015.12.182

[26] Gaur A., Klysubun W., Sonic B., Shrivastav D., Prasad J., Srivastava K. // J. Mol. Struct. 2016. V. 1121. P. 119. doi 10.1016/j.molstruc.2016.05.066

[27] Porto A.O., Pernaut J.M., Daniel H., Schilling P.J., Alves M.M.C. // Synth. Met. 1999. V. 104. P. 89. doi 10.1016/S0379-6779(99)00025-9

[28] Zhang Y., Addison O., Gostin P.F., Morrell A., Cook A.J.M.C., Liens A., $W u$ J., Ignatyev K., Stoica M., Davenport A. // J. Electrochem. Soc. 2017. V. 164. P. 1003. doi $10.1149 / 2.0671714$ jes 